\title{
RETENÇÃO PELA PALHADA, DE HERBICIDAS APLICADOS EM PRÉ- EMERGÊNCIA NA CULTURA DO MILHO, EM PLANTIO DIRETO
}

\author{
Benedito Noedi Rodrigues ${ }^{1}$, João de Lima² e Inês F. U. Yada²
}

\author{
${ }^{1}$ Engenheiro Agrônomo, Dr., Pesquisador. IAPAR. Caixa Postal 481. Londrina, PR 86001-970 \\ ${ }^{2}$ IAPAR. Caixa Postal 481. Londrina, PR 86001-970
}

\section{RESUMO}

O objetivo do trabalho foi avaliar o comportamento das misturas metolachlor/atrazine e atrazine/isoxaflutole aplicadas em pré-emergência no sistema de plantio direto de milho. Dois experimentos foram conduzidos na safra 1998/ 99 na sede do IAPAR em Londrina, PR, utilizando-se palha de aveia-preta (Avena strigosa) como cobertura morta. O delineamento dos experimentos, foi o de blocos ao acaso com cinco repetições. Os tratamentos foram constituídos pelas doses de herbicidas: zero, $0,5 \mathrm{~N}, \mathrm{~N}, 1,5 \mathrm{~N}$ e $2 \mathrm{~N}$, sendo $\mathrm{N}=$ dose normal recomendada para a cultura $(2100 / 1400 \mathrm{~g} / \mathrm{ha}$ de metolachlor/atrazine e 1660/68 g/ha de atrazine/isoxaflutole). Utilizou-se a cultivar de milho Braskalb XL 678. Os herbicidas foram aplicados com pulverizador de precisão propelido a $\mathrm{CO}_{2}$, munido com barra de seis bicos Teejet Flat Spray em leque, 80.02 , distanciados $50 \mathrm{~cm}$ entre si, com volume de calda de $200 \mathrm{l} / \mathrm{ha}$. Vinte e quatro horas após a aplicação dos herbicidas, os experimentos receberam $20,0 \mathrm{~mm}$ de irrigação $+28,3 \mathrm{~mm}$ de chuva. No dia seguinte após a chuva, foram amostrados palha e solo em todas as parcelas para análise cromatográfica de resíduos. Os resultados mostraram que, após a chuva, foi detectada no solo a metade das doses aplicadas da mistura metolachlor/atrazine. No caso da mistura atrazine/isoxaflutole, $10 \%$ de atrazine e $30 \%$ do isoxaflutole foram detectados no solo.

Palavras-chave: cromatografia, plantas daninhas, resíduos.

\section{ABSTRACT \\ Herbicide retention by mulching in corn, under no-tillage system}

The objective of this trial was to study the reactions of the residual herbicide mixtures metolachlor plus atrazine and atrazine plus isoxaflutole applied in pre-emergence for corn under no-till system. The experiment was settled in Londrina, using black oat (Avena strigosa) mulch. A randomized complete block design was used. The treatments comprised the following rates of herbicides: zero, $0.5 \mathrm{~N}, 1.0 \mathrm{~N}, 1.5 \mathrm{~N}$ and $2.0 \mathrm{~N}$ ( $\mathrm{N}=$ normal rate of herbicide). In the present study, $\mathrm{N}=2100 \mathrm{~g} / \mathrm{ha}$ metolachlor $+1400 \mathrm{~g} / \mathrm{ha}$ atrazine and $1660 \mathrm{~g} / \mathrm{ha}$ atrazine $+68 \mathrm{~g} / \mathrm{ha}$ isoxaflutole. Twenty four hours after herbicide applications, $48,3 \mathrm{~mm}$ of water was applied in the experiments. In the next day, samples of soil and straw were taken for chromatographic analysis purposes. The results showed that $50 \%$ of the metolachlor and atrazine leached from the straw to the soil. Approximately $10 \%$ of atrazine and $30 \%$ of isoxaflutole were detected in the soil after irrigation.

Key words: chromatography, weeds, residues. 


\section{INTRODUÇÃO}

O sistema de plantio direto na palha é um dos mais importantes meios de controle de erosão e de plantas daninhas do Sul do Brasil. As recomendações de herbicidas, tanto de aplicação em pré como em pós-emergência, tem sido as mesmas, tanto para o sistema de plantio direto como convencional, independentemente da quantidade de palha existente sobre o terreno.

Em trabalhos anteriores, foi verificado que alguns herbicidas são retidos na palha, mesmo ocorrendo chuvas logo após a aplicação, como é o caso do metribuzin (Banks \& Robinson, 1982), oryzalin (Banks \& Robinson, 1984) e das acetanilidas alachlor, acetochlor e metolachlor (Banks \& Robinson, 1986) e trifluralin (Rodrigues et al., 1998). Outros são facilmente lixiviados para o solo, com chuvas que ocorram 24 horas após a aplicação, como é o caso de atrazine (Rodrigues \& Almeida, 1986; Fornarolli, 1997). Esses resultados, no entanto, foram obtidos com os produtos aplicados isoladamente, nunca em misturas.

O objetivo do presente trabalho foi estudar a retenção pela palhada de algumas misturas de herbicidas, aplicadas em pré-emergência na cultura do milho, no sistema de plantio direto na palha.

\section{MATERIAL E MÉTODOS}

O trabalho foi realizado na Estação Experimental do IAPAR em Londrina, PR, em solo com $81 \%$ de argila, $8 \%$ de silte e $11 \%$ de areia, com 3,0 \% de matéria orgânica.

Foi aplicado glyphosate (1,7 1/ha de Trop $360 \mathrm{~g} / \mathrm{l})$ em toda área dos experimentos para promover a dessecação da aveia-preta (Avena strigosa), quando esta se encontrava no estádio de grão leitoso, no dia 17 de setembro de 1998. Antes da semeadura do milho foi passado um rolo, sem facas, para uniformizar a cobertura morta. Após a semeadura do milho cultivar Braskalb XL 678 peneira 20 , realizada às 11 horas do dia 14 de outubro de $1998\left(22^{\circ} \mathrm{C}\right.$ de temperatura e $60 \%$ de U.R. do ar), os herbicidas a serem testados foram aplicados no mesmo dia, em pré-emergência, com um pulverizador de precisão propelido a $\mathrm{CO}_{2}$, munido com barra de 6 bicos Teejet Flat Spray em leque, 80.02 , distanciados $50 \mathrm{~cm}$ entre si, com $3 \mathrm{~m}$ de alcance (largura da parcela) e vazão de 200 l/ha de calda. Paralelamente à aplicação, em área fora dos experimentos, em amostras ao acaso com $1 \mathrm{~m}^{2}$, foi determinado 0 peso da matéria seca da palha no momento da aplicação, obtendo-se $3700 \mathrm{~kg} / \mathrm{ha}$ de matéria seca. Para isso, a palha foi acondicionada em sacos de papel e colocada em estufa até peso constante.

O trabalho foi constituído de dois experimentos distintos, sendo um conduzido com a mistura de metolachlor/ atrazine e outro com a mistura de atrazine/isoxaflutole, que pertencem aos seguintes grupos químicos: metolachlor $=$ acetanilidas, atrazine $=$ triazinas e isoxaflutole $=$ benzoil isoxazoles. Os experimentos foram delineados em blocos ao acaso com 5 tratamentos e cinco repetições cada um. Os tratamentos foram constituídos pelas seguintes doses de herbicidas: zero, $0,5 \mathrm{~N}, \mathrm{~N}, 1,5 \mathrm{~N}$ e $2 \mathrm{~N}$, onde $\mathrm{N}=$ dose normal recomendada pelo fabricante. No primeiro experimento, a dose normal foi de 2100/1400 g/ha de metolachlor/ atrazine (7,0 1/ha de Primestra SC). No segundo experimento a dose normal foi de $1660 / 68 \mathrm{~g} /$ ha de atrazine/isoxaflutole ( $2.0 \mathrm{~kg} / \mathrm{ha}$ de Alliance WG). As parcelas tiveram as dimensões de 3,0 m x 6,0 m (18,0 $\left.\mathrm{m}^{2}\right)$, sendo que, nas laterais, foram deixadas faixas sem palha, não tratadas, que foram utilizadas como termo de comparação nas avaliações visuais. Vinte e quatro horas após a aplicação dos herbicidas todo o experimento foi irrigado por aspersão, aplicando-se $20 \mathrm{~mm}$ de água. A finalidade desta foi auxiliar a lixiviação dos herbicidas da palha para o solo. Logo após a irrigação ocorreu uma chuva natural de $28,3 \mathrm{~mm}$, perfazendo, portanto, uma precipitação de $48,3 \mathrm{~mm}$. No dia seguinte após a chuva foram amostrados solo e palha de todas as parcelas, com amostrador de $10 \times 10 \mathrm{~cm}$ com $10 \mathrm{~cm}$ de profundidade. As amostras foram levadas ao Laboratório de Ecofisiologia do IAPAR para análise cromatográfica de resíduos.

As espécies de plantas daninhas que ocorreram nos experimentos foram Brachiaria plantaginea, Euphorbia heterophylla e Bidens pilosa. No experimento de campo foram feitas avaliações visuais em percentagem de controle e fitotoxicidade (0-100\%) aos 30 e 50 dias após a semeadura (DAS). Foi também determinada a produção de grãos de milho em $\mathrm{kg} / \mathrm{ha}$, a $14 \%$ de umidade. Todos os dados foram submetidos à análise de regressão.

\section{RESULTADOS E DISCUSSÃO}

\section{a) Metolachlor/atrazine}

A mistura metolachlor/atrazine praticamente não provocou fitotoxicidade no milho. Os valores correspondentes às porcentagens de leve injúria no milho, com avaliações feitas aos 30 e 50 dias após a semeadura, podem ser observados na Figura 1. A produção aumentou com o aumento da dose da mistura (Figura 2).

O controle da B. plantaginea cresceu com o aumento da dose do herbicida, chegando a um nível máximo de $90 \%$ nas doses maiores, aos 30 DAS. Nesta avaliação, havia 88 plantas $/ \mathrm{m}^{2}$ nas faixas laterais utilizadas com termo de comparação. Na dose normal não passou dos $80 \%$ de controle. Nas parcelas sem herbicidas o controle foi de $40 \%$ aos 30 DAS e $20 \%$ aos 50 DAS (Figura 3 ). 


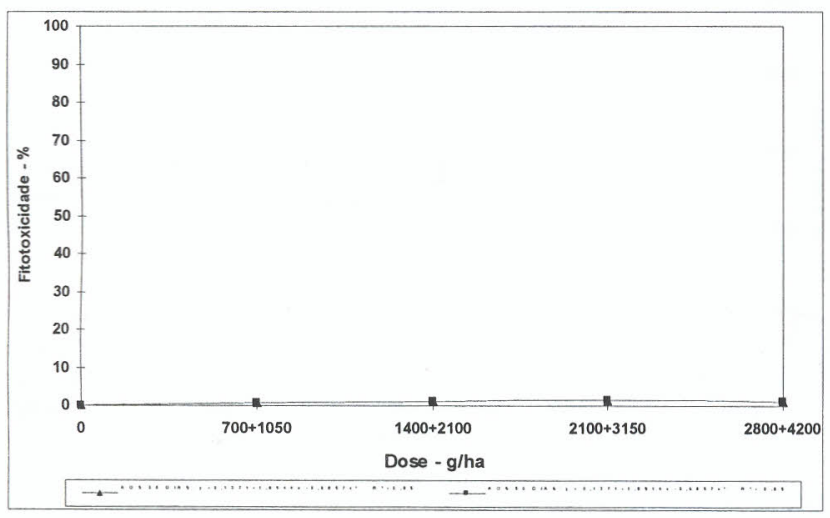

Figura 1. Fitotoxicidade aos $\mathbf{3 0}$ e $\mathbf{5 0}$ dias após a semeadura do milho, causada pela mistura de atrazine/ metolachlor.

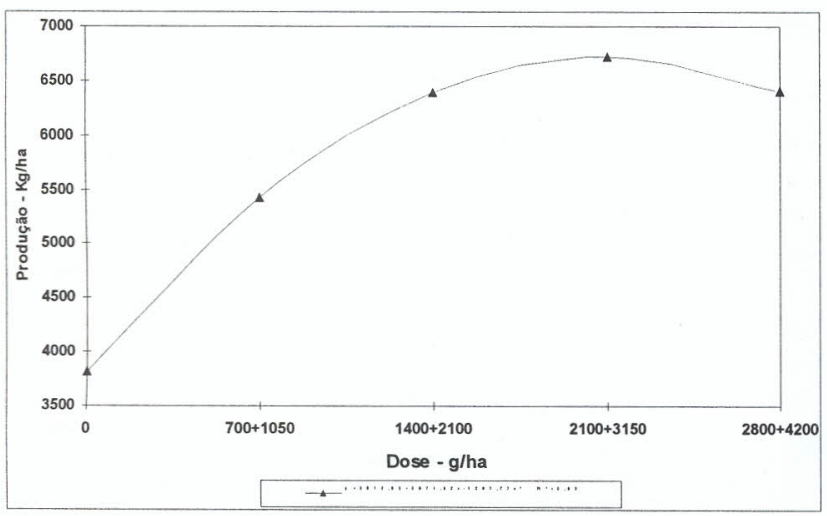

Figura 2. Produção de grãos de milho conforme as doses da mistura de atrazine/metolachlor.

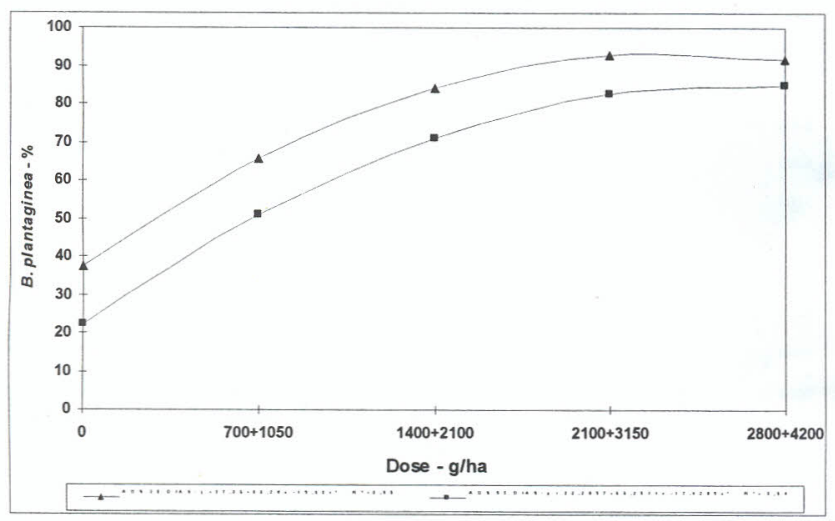

Figura 3. Percentagem de controle de $\boldsymbol{B}$. plantaginea aos 30 e 50 dias após a semeadura do milho, obtida pela mistura de atrazine/metolachlor.
O controle de E. heterophylla e de B. pilosa foi semelhante (Figuras 4 e 5). Os maiores valores (entre 90 e $100 \%$ ), foram obtidos com a dose 1,5N (3150/2100 g/ha de metolachlor/atrazine) na avaliação realizada aos 30 DAS. Nessa época, havia 32 plantas $/ \mathrm{m}^{2}$ de $E$. heterophylla e 9 plantas $/ \mathrm{m}^{2}$ de B. pilosa nas faixas comparativas. Aos 50 DAS, a tendência de controle se manteve a mesma, evidentemente com valores inferiores aos observados na avaliação anterior.

As análises cromatográficas de resíduos mostraram que o teor de metolachlor detectado no solo após uma irrigação de $20 \mathrm{~mm}$ e chuva de $28,3 \mathrm{~mm}$, ocorrida 24 horas após a aplicação, era de aproximadamente $43 \%$ do total do produto aplicado na dose normal, percentual este que se manteve também com as doses maiores (Figura 6). Como o percentual detectado na palha também foi baixo, não passando dos 7\% das doses utilizadas, perfazendo um total de $50 \%$ entre palha + solo, observa-se que $50 \%$ do metolachlor aplicado não foi recuperado por cromatografia, podendo ter sido lixiviado para as camadas mais profundas do solo devido à chuva ocorrida, ou se perdido por outras formas. Esses resultados coincidem com os obtidos anteriormante por Banks \& Robinson (1986) quando utilizaram metolachlor isoladamente. Os autores verificaram que uma chuva de $12,5 \mathrm{~mm}$ ocorrida logo após a aplicação, provocou a lixiviação de menos de $50 \%$ do metolachlor da palha para o solo, em cobertura com $2240 \mathrm{~kg} / \mathrm{ha}$ de palha de trigo.

$\mathrm{O}$ atrazine, na presente mistura, teve comportamento semelhante ao metolachlor (Figura 7) sendo detectado aproximadamente $50 \%$ no solo. Os dados do presente trabalho, diferem dos obtidos por Fornarolli (1997). Naquela oportunidade, o autor verificou que mais de $80 \%$ do atrazine foi lixiviado da palha para o solo após uma irrigação de 20 mm ocorrida 24 horas após a aplicação do herbicida, quando aplicado isoladamente. A mistura com o metolachlor ou a diferença de precipitação pode ter influenciado nesta diferença de resultados.

Analisando os dados obtidos de forma conjunta, verificou-se que o controle das plantas daninhas presentes no experimento foi obtido com a metade das doses de cada tratamento, uma vez que somente em torno de 50\% da dose de cada herbicida foi detectada no solo. Outro aspecto importante é que, apesar da palhada existente sobre o terreno (no presente caso, $3700 \mathrm{~kg} / \mathrm{ha}$ de matéria seca), o uso de herbicidas aplicados em pré-emergência não pode ser dispensado, uma vez que o controle das ervas obtido nos tratamentos sem herbicidas não passou dos 30-35\% nas avaliações visuais realizadas. Portanto, somando-se os efeitos físico e alelopático da cobertura morta da aveia (Almeida, 1988), com o efeito dos herbicidas, obteve-se o controle satisfatório das plantas daninhas presentes. 


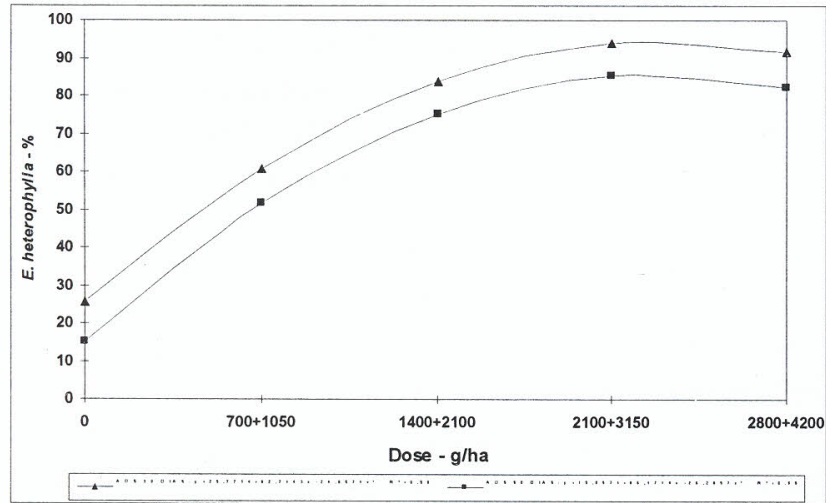

Figura 4. Percentagem de controle de E. heterophylla aos 30 e $\mathbf{5 0}$ dias após a semeadura do milho, obtida pela mistura de atrazine/metolachlor.

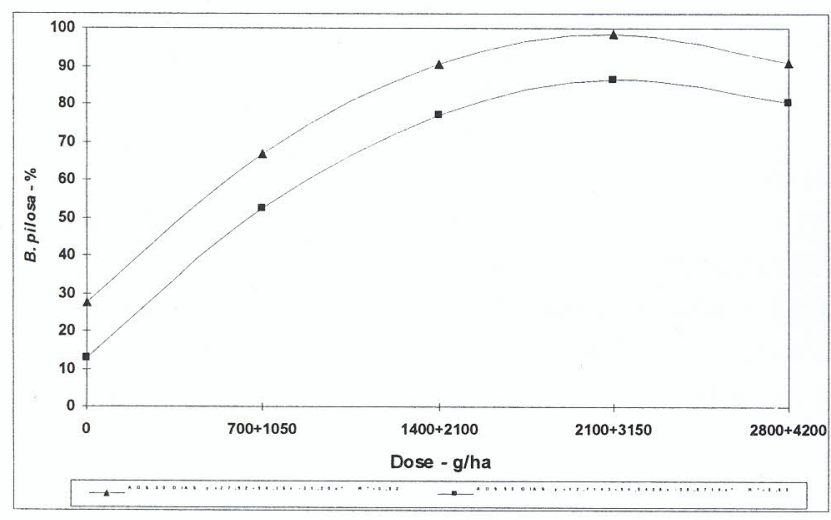

Figura 5. Percentagem de controle de B. pilosa aos 30 e 50 dias após a semeadura do milho, obtida pela mistura de atrazine/metolachlor.

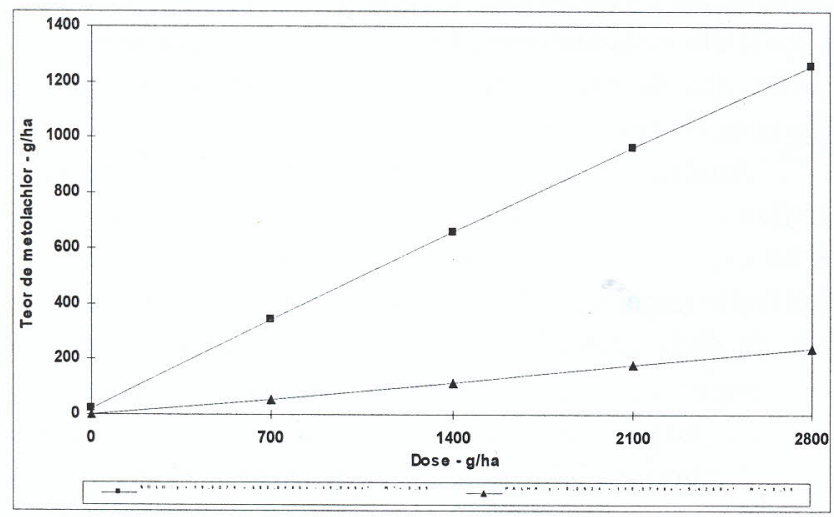

Figura 6. Teor de metolachlor no solo e na palha em função da dose deste produto após uma chuva de $48,3 \mathrm{~mm}$, ocorrida 24 horas depois da aplicação da mistura de atrazine/metolachlor.

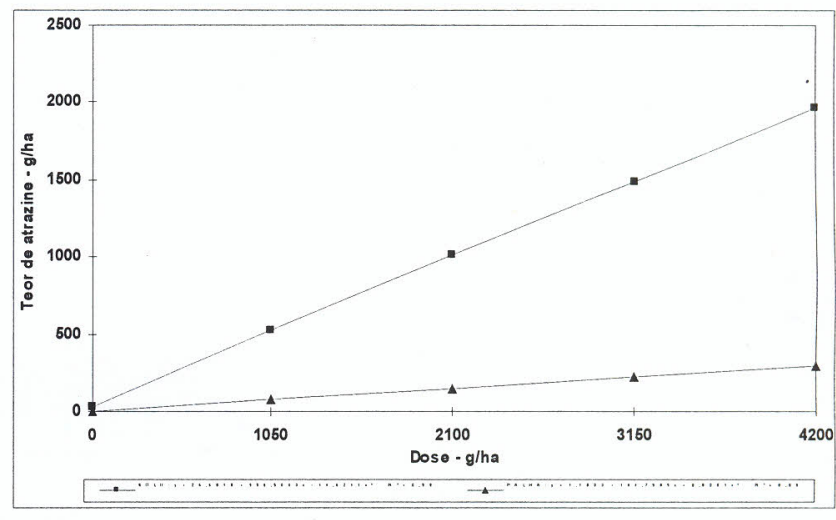

Figura 7. Teor de atrazine no solo e na palha em função da dose deste produto após uma chuva de $48,3 \mathrm{~mm}$, ocorrida 24 horas depois da aplicação da mistura de atrazine/metolachlor.

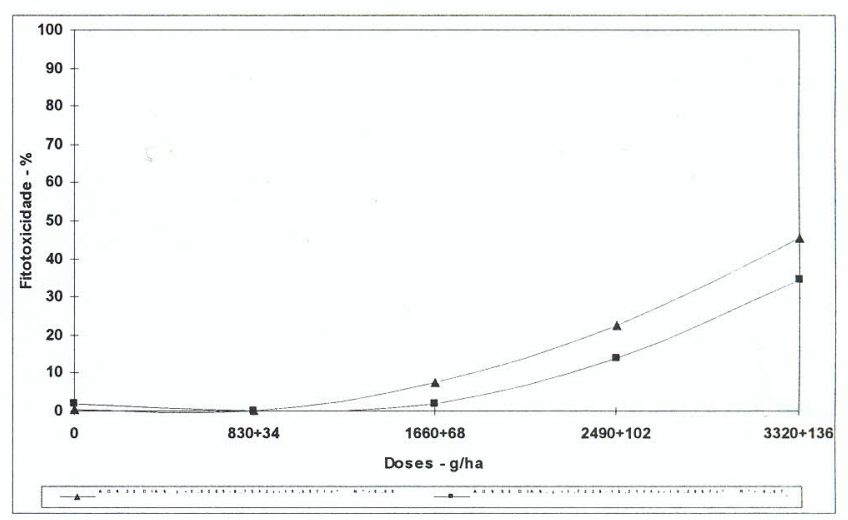

Figura 8. Fitotoxicidade aos $\mathbf{3 0} \mathbf{5 0}$ dias após a semeadura do milho, causada pela mistura de atrazine + isoxaflutole.

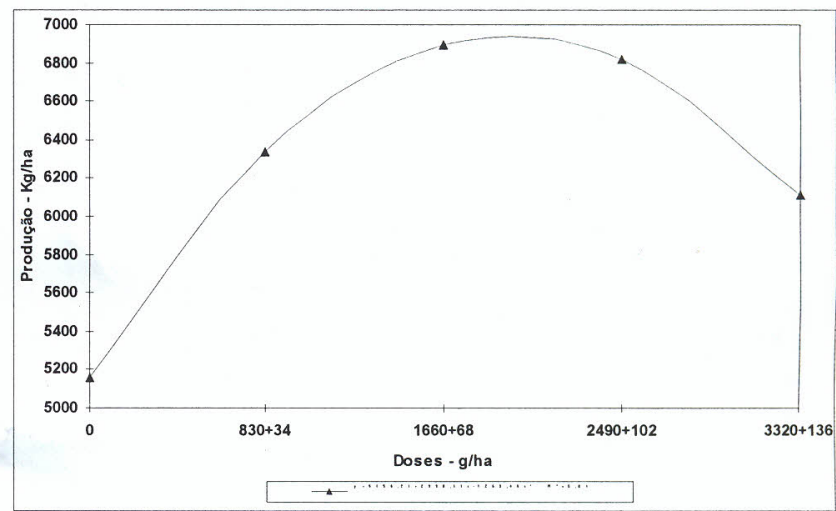

Figura 9. Produção de grãos de milho conforme as doses da mistura de atrazine + isoxaflutole.

Revista Brasileira de Herbicidas v.1, n.2, 2000 


\section{b) Atrazine/isoxaflutole}

A mistura atrazine/isoxaflutole provocou alguma fitotoxicidade no milho, provocada principalmente por redução no crescimento, notadamente na dose maior. Os valores correspondentes às percentagens de injúria no milho, com avaliações feitas aos 30 e 50 dias após a semeadura (DAS), podem ser observados na Figura 8. A produção de grãos foi maior com a dose normal, caindo com as doses maiores (Figura 9).

O controle de $B$. plantaginea, E. heterophylla e B. pilosa, as tres espécies presentes neste experimento, nas mesmas densidades populacionais citadas no experimento anterior, aumentou com o aumento da dose dos componentes da mistura (Figuras 10, 11 e 12), sendo que, na dose normal, o controle não foi satisfatório.

Somando-se os teores de atrazine obtidos na palha e no solo através das análises cromatográficas de resíduos (Figura 13), observa-se que, em praticamente todas as doses, a soma é de aproximadamente 17 a $18 \%$ das doses originalmente aplicadas, o que demonstra a ocorrência de uma perda substancial do produto. Esses dados são bem diferentes daqueles obtidos por Fornarolli (1997) com atrazine aplicado isoladamente. Naquele trabalho, o autor verificou que, em condições de menor quantidade de chuva (apenas $20 \mathrm{~mm}$ ), mais de $80 \%$ do atrazine foi detectado no solo (10 $\mathrm{cm}$ de profundidade).

Os teores de isoxaflutole foram detectados apenas no solo, uma vez que houve problemas analíticos com o produto na palha (Figura 14). Observa-se que aproximadamente $30 \%$ do total aplicado foi detectado no solo após a irrigação de $20,0 \mathrm{~mm}$ e a chuva de $28,3 \mathrm{~mm}$. Os outros $70 \%$ poderiam ter ficado retido na palha (dados não obtidos), ou ter lixiviado para as camadas mais profundas do solo.

\section{CONCLUSÕES}

A mistura metolachlor/atrazine, aplicada em préemergência da cultura e das plantas daninhas, sobre a palhada de aveia-preta, no sistema de plantio direto do milho, conseguiu atingir o solo com praticamente metade da dose e, complementada com os efeitos físicos e alelopáticos da palhada, é eficiente no controle de Brachiária plantaginea, Euphorbia heterophylla e Bidens pilosa.

A mistura atrazine/isoxaflutole, aplicada nas mesmas condições, consegue atingir o solo com $10 \%$ da dose atrazine e $30 \%$ da dose do isoxaflutole. A dose mais eficiente desta mistura foi de $1,5 \mathrm{~N}(2490+102 \mathrm{~g} / \mathrm{ha}$ de atrazine/ isoxaflutole).

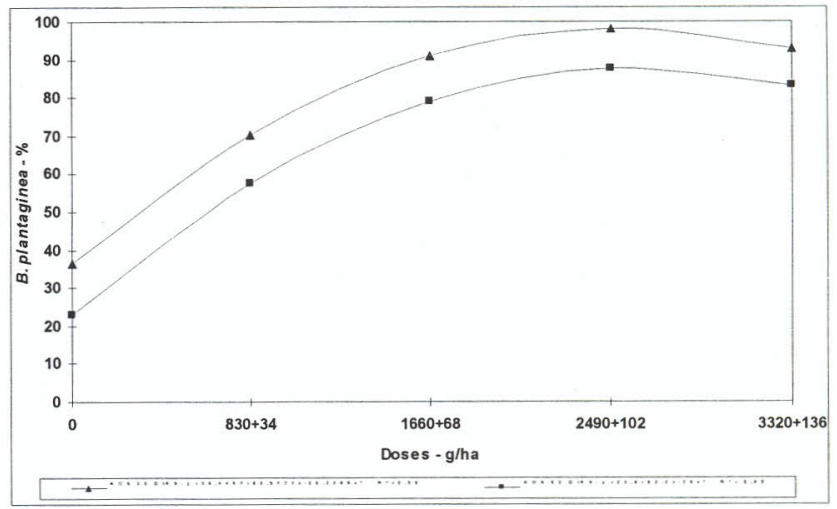

Figura 10. Percentagem de controle de $B$. plantaginea aos 30 e 50 dias após a semeadura do milho, obtida pela mistura de atrazine + isoxaflutole.

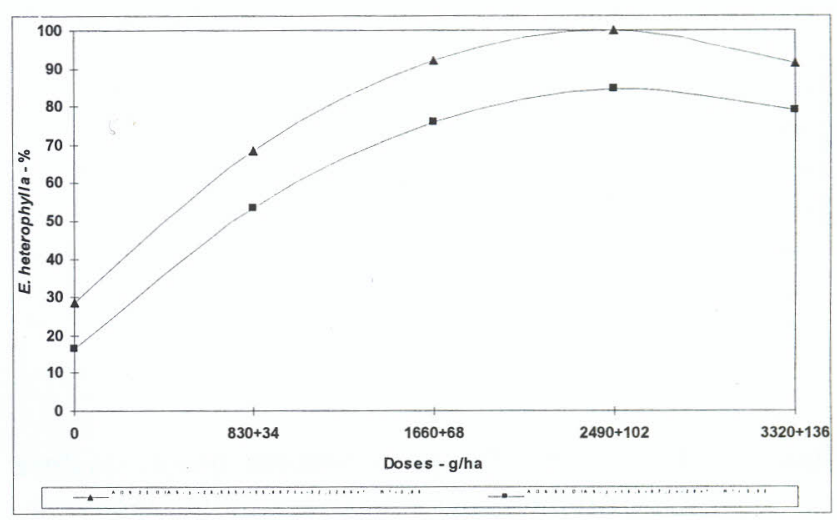

Figura 11. Percentagem de controle de E. heterophylla aos 30 e 50 dias após a semeadura do milho, obtida pela mistura de atrazine + isoxaflutole.

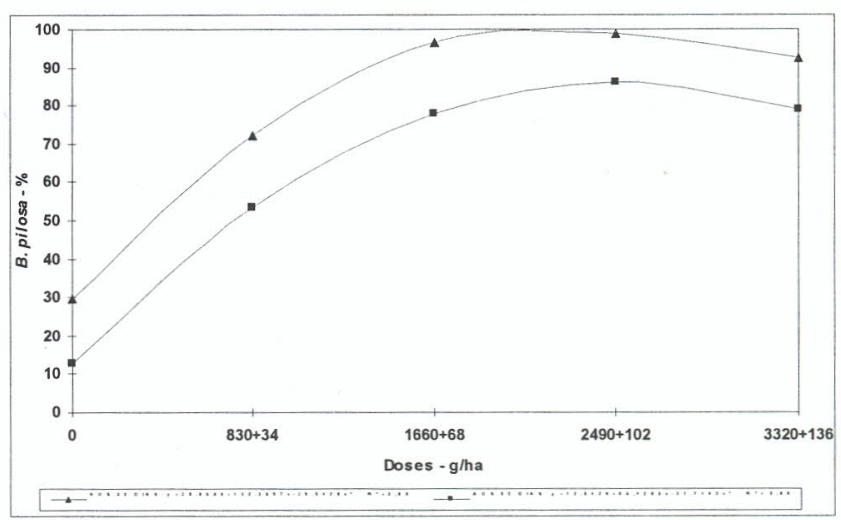

Figura 12. Percentagem de controle de B. pilosa aos 30 e 50 dias após a semeadura do milho, obtida pela mistura de atrazine + isoxaflutole. 


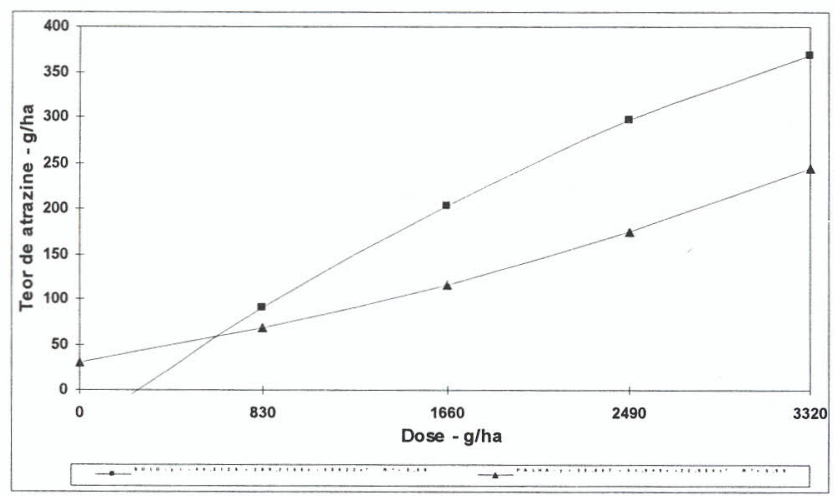

Figura 13. Teor de atrazine no solo e na palha em função da dose deste produto após uma chuva de $48,3 \mathrm{~mm}$, ocorrida 24 horas depois da aplicação da mistura de atrazine + isoxaflutole.

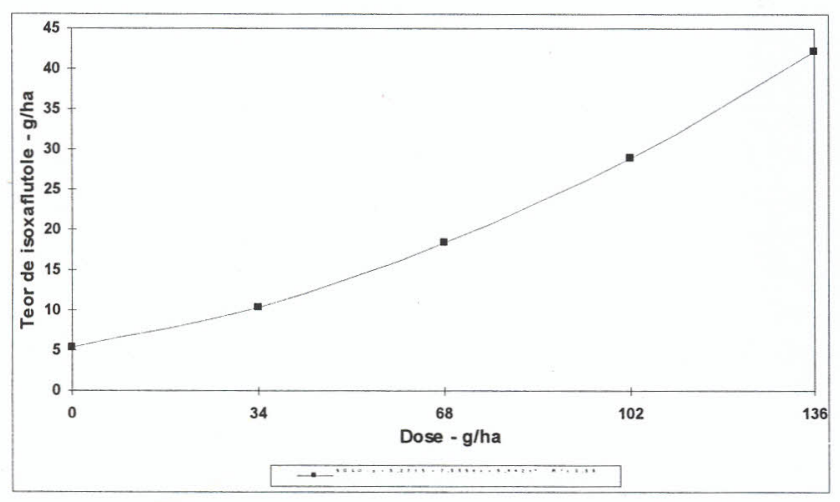

Figura 14. Teor de isoxaflutole no solo em função da dose deste produto após uma chuva de $48,3 \mathrm{~mm}$, ocorrida 24 horas depois da aplicação da mistura de atrazine+isoxaflutole.

\section{LITERATURA CITADA}

ALMEIDA, F.S. A alelopatia e as plantas. Londrina, IAPAR, 1988.60 p. (Circular IAPAR, 53).

BANKS, P.A.; ROBINSON, E.L. The influence of straw mulch on the soil reception and persistence of metribuzin. Weed Science, Champaign, v.30, n.2, p.164-8. 1982.

BANKS, P.A.; ROBINSON, E.L. The fate of oryzalin applied to straw-mulched and non-mulched soils. Weed Science, Champaign, v.32, p.269-272, 1984.

BANKS, P.A.; ROBINSON, E.L. Soil reception and activity of acetochlor, alachlor and metolachlor as affected by wheat (Triticum aestivum), atraw irrigation. Weed Science, Champaign, v.34, p.607-611, 1986.

FORNAROLLI, D.A. Influência da cobertura morta no comportamento do herbicida atrazine. Londrina, PR: UEL, 1997. Dissertação (Mestrado.em Agronomia). Universidade Estadual de Londrina, 1997.

RODRIGUES, B.N.; ALMEIDA, F.S. Influência da cobertura morta no comportamento dos herbicidas atrazine e metolachlor no sistema de plantio direto. In: FUNDAÇÃO INSTITUTO AGRONÔMICO DO PARANÁ, Londrina, PR. Resultados de pesquisa da Área de Herbologia, safras 1984/85 e 1985/86. Londrina, 1986. (Mimeografado).

RODRIGUES, B.N.; LIMA, J; YADA, I.F.U.; FORNAROLLI, D.A. Influência da cobertura morta no comportamento do herbicida trifluralin. Planta Daninha, v.16, n.2, p. 163173, 1998. 